\title{
Correlation between the dimensions of diaphragm movement, respiratory functions and pressures in accordance with the gross motor function classification system levels in children with cerebral palsy
}

\author{
Hae-Yeon Kwon, Byeong-Jo Kim* \\ Department of Physical Therapy, College of Nursing, Healthcare Sciences and Human Ecology, Dong-eui University, Busan, Korea
}

This study was executed as correlation study to investigate the correlation between the dimensions of diaphragm movement, and respiratory functions and pressures in accordance with the Gross Motor Function Classification System (GMFCS) levels on children with cerebral palsy as the participants. Forty-three children in the age range of 5-13 years diagnosed with cerebral palsy as the research participants were divided into three groups (levels I, II, and III) through systematic stratified random sampling in accordance with their GMFCS levels. Pearson correlation analysis was executed to examine the correlation between dimensions of diaphragm movement, and respiratory functions and pressures in accordance with the GMFCS levels of the participants. There was no significant correlation between the dimensions of diaphragm movement, and respiratory functions and pressures in all of the three groups in accordance with the GMFCS levels of the participants. Therefore, it is deemed that although measurement of the dimensions of diaphragm movement of children with cerebral palsy by using diagnostic ultrasonic M-mode imaging device can be considered as auxiliary tool in predicting the breathing capabilities, it cannot be used as independent measurement equipment.

Keywords: Cerebral palsy, Diaphragm movement, Respiratory function, Respiratory pressure

\section{INTRODUCTION}

Cerebral palsy is a nonprogressive impairment that occurs in the brain of fetus or infant and is a clinical syndrome that induces activity limitation by causing disabilities in movement and posture (Rosenbaum et al., 2007). Cerebral palsy has symptoms of muscle tone and neuromotor disabilities due to damage to the brain (Knox and Evans, 2002), as well as muscle weakness, inappropriate movement velocity, increase in energy consumption during activities and degradation of the functions of heart and lung, etc. (Bax et al., 2005). In particular, children with cerebral palsy are not able to appropriately control the inspiration and expiration cycle due to dysfunction of respiration muscles and displays accompaniment of respiratory muscle weakness due to the abnormal movement of diaphragm and costovertebral joint. Due to these problems, secondary medical problems including aspiration pneumonia, reduction in airway clearance ability, purulent diseases, thoracic scoliosis, and blocking of upper respiratory tract, etc. are manifested (Fitzgerald et al., 2009). Therefore, breathing problems in children with cerebral palsy are related to the reduction in the mobility and structural deformation of rib cage due to poor activities of respiratory muscles, although the brain damage in itself is not the cause (Ersöz et al., 2006). That is, since the muscles in the chest are weakened and voluntary breathing capabilities are reduced due to limited rib cage mobility (Mead et al., 1985), such reduction in respiratory function is related to the limitation in the physical performance levels (Engel-Yeger et al., 2009).

Although children with cerebral palsy display significant differ-
*Corresponding author: Byeong-Jo Kim (ib https://orcid.org/0000-0002-7248-0520 Department of Physical Therapy, College of Nursing, Healthcare Sciences and Human Ecology, Dong-eui University, 176 Eomgwang-ro, Busanjin-gu, Busan 47340, Korea

Tel: +82-51-8904221, Fax: +82-505-1826881, E-mail: pt123@deu.ac.kr

Received: August 19, 2018 / Accepted: October 5, 2018
This is an Open Access article distributed under the terms of the Creative Commons Attribution Non-Commercial License (http://creativecommons.org/licenses/by-nc/4.0/) which permits unrestricted non-commercial use, distribution, and reproduction in any medium, provided the original work is properly cited. 
ence in general respiratory function test in comparison to normal children of same age (Wang et al., 2012), it is very difficult to evaluate the breathing capabilities of children with cerebral palsy with weakened respiratory muscles and problems in muscular coordination in actual clinical situations (Seddon and Khan, 2003). In particular, they tend to rely on the functions of diaphragm completely due to insufficient development of appropriate ventilatory function, and weak movements of intercostal muscles and mediastinum during neonatal and infant stages (Mok et al., 1991). As such, if diaphragm, which is the main muscle in breathing, is damaged, serious problems related to breathing occur (de Leeuw et al., 1999). Therefore, it is known that functional evaluation of diaphragm movement that contributes to the periodic breathing pattern is clinically very important (Anraku and Shargall, 2009), assessment of diaphragm, which is a composite thoracic-abdominal muscle is relatively very difficult. Accordingly, evaluation of diaphragm movement by using diagnostic ultrasonic M-mode imaging device is not only a method that can be applied to participants noninvasively but also a measurement tool with the advantage of being able to relatively easily find the dysfunctions of diaphragm (Epelman et al., 2005).

According to evaluation with diagnostic ultrasonic imaging device, it is reported that although the contraction of diaphragm at the time of normal in halation appears as upward flexion under the projection image since it moves towards the ultrasonic converter, relaxation of diaphragm at the time of expiration appears as downward flexion under the projection image since it moves in the opposite direction of ultrasonic converter with assuming of sharply pointed shape at the conversion zone at the last (Ayoub et al., 1997). The range of normal diaphragm movement needs to be greater than $4 \mathrm{~mm}$ and it can be deemed to have normal range if there is difference of less than $50 \%$ in the dimensions of diaphragm movement on both sides. However, in the case of diaphragm dysfunction, it is bent upward at the time of inspiration and bent downward at the time of expiration with creation of gently bent shape in the conversion zone, as well as corresponds to the cases in which the difference between the dimensions of diaphragm movement on the both sides is more than $50 \%$ with the range of the diaphragm movement below $4 \mathrm{~mm}$. Lastly, if diaphragm is paralyzed, it is downward flexed at the time of inspiration and upward flexed at the time of expiration, thereby creating gently bent shape in the conversion zone as well as generation of diverse differences not only in the range of diaphragm movement but also is the dimensions of diaphragm movement on both sides, in contrast to the contraction of normal diaphragm (Urvoas et al.,
1994).

Although the aforementioned ultrasonic imaging device for diagnosis is used clinically for evaluation of diaphragm movement, there are only reports of preceding researches on some of the patients including the research on children suspected of diaphragm paralysis (Riccabona et al., 1998) and evaluation of dimensions of diaphragm movement of adult hemiplegia patient by using ultrasonography (de Almeida et al., 2011; Voyvoda et al., 2012), etc. As such, there is substantial lack of research that compares diaphragm movements by using ultrasonic imaging device on children with cerebral palsy. Therefore, the purpose of this study is to analyze the correlation between the dimensions of diaphragm movement, and respiratory functions and pressures in accordance with the Gross Motor Function Classification System (GMFCS) levels, and to determine whether the diagnostic ultrasonic Mmode imaging device is useful measurement equipment in evaluating the extent of breathing of children with cerebral palsy as participants.

\section{MATERIALS AND METHODS}

\section{Participants and design}

This study was executed as correlation study to investigate the correlation between the dimensions of diaphragm movement, and respiratory functions and pressures in accordance with the GMFCS levels on children with cerebral palsy as the participants. Prior to the execution of this study, approval of the bio-ethics review committee of Dong-eui University that we will be responsible for the protection of the human rights, dignity and safety of the participants was acquired (IRB No. DIRB-201601-HR-R-003).

Forty-three children with cerebral palsy as the research participants were divided into three groups, namely the stages I, II, and III through systematic stratified random sampling in accordance with their GMFCS levels. The detailed selection criteria for the research participants included the following. First, children in the age range of 5-13 years diagnosed with cerebral palsy of spastic type by specialist in rehabilitation medicine/neurosurgery. Second, children with GMFCS levels of I-III. Third, children capable of performing measurement test in accordance with the instructions of the researcher. Fourth, children with no difficulty in communicating and interacting with the researcher. General characteristics and past medical histories of the participants are given in the Table 1.

After having explained the purpose, method, risks, and inconveniences of the research in detail to the research participants and guardian (legal representative) prior to the commencement of this 
Table 1. General characteristics and medical history of the participants $(n=43)$

\begin{tabular}{lccc}
\hline Characteristic & GMFCS I $(\mathrm{n}=14)$ & GMFCS $\|(\mathrm{n}=15)$ & GMFCS III $(\mathrm{n}=14)$ \\
\hline Gender, male:female & $5: 9$ & $6: 9$ & $6: 8$ \\
Age $(\mathrm{yr})$ & $7.35 \pm 2.76$ & $7.60 \pm 2.79$ & $8.07 \pm 2.53$ \\
Height $(\mathrm{cm})$ & $112.82 \pm 16.10$ & $115.59 \pm 16.03$ & $121.86 \pm 14.09$ \\
Weight $(\mathrm{kg})$ & $21.52 \pm 7.34$ & $24.07 \pm 8.93$ & $23.59 \pm 6.56$ \\
Pregnancy week (wk) & $35.50 \pm 3.44$ & $34.71 \pm 4.14$ & $33.21 \pm 4.48$ \\
Birth weight (g) & $2,630.67 \pm 609.26$ & $2,497.43 \pm 701.18$ & $2,187.71 \pm 538.16$ \\
Incubator care (wk) & $4.00 \pm 3.64$ & $4.64 \pm 4.95$ & $11.14 \pm 19.18$
\end{tabular}

Values are presented as number or mean \pm standard deviation.

GMFCS, Gross Motor Function Classification System.

study, signed "letter of consent of research participants" that they are participating in this study voluntarily were acquired.

\section{Measurements}

Dimensions of diaphragm movement of the participants were measured by using diagnostic ultrasonic imaging device (Aloka, SSD-3500X; Aloka Co. Ltd., Tokyo, Japan) with M-mode option. Firstly, children with cerebral palsy were instructed to lie down in supine posture on examination table and sufficient quantity of ultrasonic gel was spread on probe and skin in abdomen. Accurate location of diaphragm of the child with cerebral palsy was confirmed through the ultrasonic image and palpation of the operator (Urvoas et al., 1994). While the children with cerebral palsy were performing spontaneous breathing and deep breathing, dimensions of hemidiaphragm movement in the body section of the dominant arm was measures 3 times repetitively by using 3.5- to $5-\mathrm{MHz}$ ultrasonic frequency, and mean value of the measurements was computed. However, measurement of the dimensions of diaphragm movement was performed by a single operator who sufficiently learned and practiced the methods of using diagnostic ultrasonic imaging device in advance in order to minimize the difference between the operators using the measurement device and to secure the consistency of measurement results.

The respiratory function of children with cerebral palsy was measured by using Spirometer Pony FX (Cosmed Ltd., Albano Laziale, Italy) after having confirmed that the health states of the children are fair. In addition, repetitive education on children with cerebral palsy was performed in advance in order for them to properly understand the measurement devices and methods, and to accurately perform the measurement procedures. Respiratory functions were measured after having instructed the children with cerebral palsy to sit on chair with back support while wearing clothes that allowed comfortable movement of their body. Children with cerebral palsy were then instructed to take $3-4$ natural breathe as they would in their daily life activities before taking deepest and quickest inspiration and expiration possible in order to measure forced vital capacity (FVC), forced expiratory volume at $1 \mathrm{sec}\left(\mathrm{FEV}_{1}\right)$, and peak expiratory flow (PEF). In particular, precautions were taken to ensure that there is no occurrence of coughing, leaking of air and erroneous start, etc. at the time of breathing with the Guidelines of American Thoracic Society as the reference. After having taken 3 repetitive measurements, optimal measurement value was selected.

After having completed the respiratory function tests on children with cerebral palsy, the participants were allowed to have rest over sufficient period of time to prevent fatigue in respiration muscles and dizziness arising from repeated measurements. Respiration pressure was measured while the children with cerebral palsy were inhaling and exhaling as they would during normal daily activities by keeping the mouthpiece to the lips as closely as possible to ensure there is no leakage of air. For the maximal inspiratory pressure, the participants were instructed to maintain deepest and fasted inspiration possible for more than 2 sec until signal sound is heard from the measurement equipment after having put on the nose clip on the participant when exhaling maximally as close to the residual air volume as possible. For the maximal expiratory pressure, the participants were instructed to maintain deepest and fasted expiration possible for more than 2 sec until signal sound is heard from the measurement equipment after having put on the nose clip on the participant when inhaling maximally as close to the total lung capacity as possible.

However, measurement of the dimensions of diaphragm movement, respiratory functions and pressures of the participants by using the aforementioned two diagnostic equipment was performed by a single operator who sufficiently learned, familiarized with and practiced the methods of using both of the equipment in advance in order to minimize the error of the operator in the resultant values, and to secure the reliability of the measurement results. In addition, the guardian (legal representative) of the participant was allowed to be present at the time taking measurements with aforementioned diagnostic equipment.

\section{Statistical analysis}

Data obtained in this study was analyzed by using IBM SPSS Statistics ver. 25.0 (IBM Co., Armonk, NY, USA), and the significance level to verify statistical significance was set at 0.05 . General characteristics of the research participants were computed by means of frequency and descriptive statistics with the parametric method after having confirmed the normality of measurement 
Table 2. Comparison of the dimensions of diaphragm movement, and respiratory functions and pressures in accordance with the GMFCS levels

\begin{tabular}{|c|c|c|c|c|c|}
\hline Variable & GMFCS I $(n=14)$ & GMFCS $\|(n=15)$ & GMFCS III (n=14) & $F$ & $P$-value \\
\hline \multicolumn{6}{|c|}{ Dimensions of diaphragm movement } \\
\hline Spontaneous breathing (cm) & $1.59 \pm 0.05^{c)}$ & $1.4 \pm 0.05^{b)}$ & $1.11 \pm 0.08^{b, c)}$ & 206.049 & $0.000^{* *}$ \\
\hline Deep breathing (cm) & $2.60 \pm 0.29^{c)}$ & $2.56 \pm 0.08^{b)}$ & $2.26 \pm 0.06^{\mathrm{b}, \mathrm{c})}$ & 15.910 & $0.000^{* *}$ \\
\hline \multicolumn{6}{|l|}{ Respiratory functions } \\
\hline FVC $(\mathrm{L})$ & $1.60 \pm 0.44^{\mathrm{a}, \mathrm{c})}$ & $1.43 \pm 0.06^{a, b)}$ & $1.14 \pm 0.12^{b, c)}$ & 107.852 & $0.000^{* *}$ \\
\hline $\mathrm{FEV}_{1}(\mathrm{~L})$ & $1.40 \pm 0.04^{a, c)}$ & $1.31 \pm 0.05^{a, b)}$ & $1.12 \pm 0.07^{b, c)}$ & 85.792 & $0.000^{* *}$ \\
\hline PEF (L/sec) & $2.72 \pm 0.09^{a, c)}$ & $2.58 \pm 0.07^{a, b)}$ & $2.19 \pm 0.11^{b, c)}$ & 124.308 & $0.000^{* *}$ \\
\hline \multicolumn{6}{|l|}{ Respiratory pressures } \\
\hline $\mathrm{MIP}\left(\mathrm{cmH}_{2} \mathrm{O}\right)$ & $34.51 \pm 1.85^{c)}$ & $32.61 \pm 1.53^{b)}$ & $24.75 \pm 3.28^{b, c)}$ & 69.284 & $0.000^{* *}$ \\
\hline $\mathrm{MEP}\left(\mathrm{cmH}_{2} \mathrm{O}\right)$ & $43.98 \pm 4.04^{c)}$ & $43.80 \pm 2.07^{b)}$ & $34.99 \pm 3.11^{b, c)}$ & 37.576 & $0.000^{* *}$ \\
\hline
\end{tabular}

Values are presented as mean \pm standard deviation.

GMFCS, Gross Motor Function Classification System; FVC, forced vital capacity; FEV1, forced expiratory volume in 1 sec; PEF, peak expiratory flow; MIP, maximal inspiratory pressure; MEP, maximal expiratory pressure.

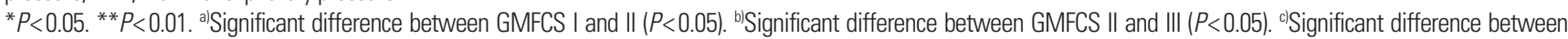
GMFCS I and III $(P<0.05)$.

variables through Kolmogorov-Smirnov analysis. One-way analysis of variance was performed to analyze the difference in the dimensions of diaphragm movement, respiratory functions and pressures between the three groups in accordance with the GMFCS levels of the participants. Boneferroni test was used for post boc analysis. In addition, Pearson correlation analysis was executed to examine the correlation between dimensions of diaphragm movement, and respiratory functions and pressures in accordance with the GMFCS levels of the participants.

\section{RESULTS}

The results of comparative analysis of the mean values of the dimensions of diaphragm movement, respiratory functions and respiratory pressures between the three groups in accordance with the GMFCS levels of the participants are presented in the Table 2.

There were significant differences in all of dimensions of diaphragm movement, respiratory functions and pressures of the participants between the three groups in accordance with the GMFCS levels $(P<0.01)$. As the results of post-hoc verification of the dimensions of diaphragm movement, there were significant differences in spontaneous breathing and deep breathing between GMFCS levels I and III, and between GMFCS levels II and III. As the results of post hoc verification of the respiratory functions, there were significant differences in FVC, $\mathrm{FEV}_{1}$, and PEF between GMFCS levels I and II, between GMFCS levels I and III, and between GMFCS levels II and III. As the results of post hoc verification of the respiratory pressures, there were significant differences between GMFCS levels I and III, and between GMFCS levels II and III.
Table 3. Correlation between dimensions of diaphragm movement, and respiratory functions and pressures in accordance with the GMFCS levels

\begin{tabular}{lccc}
\hline Variable & GMFCS I $(n=14)$ & GMFCS II $(n=15)$ & GMFCS III $(n=14)$ \\
\hline Spontaneous breathing & & & \\
FVC & 0.036 & -0.260 & 0.104 \\
FEV ${ }_{1}$ & -0.432 & -0.501 & -0.217 \\
PEF & 0.099 & -0.218 & 0.047 \\
MIP & -0.030 & 0.419 & 0.108 \\
MEP & -0.003 & 0.322 & -0.261 \\
Deep breathing & & & \\
FVC & -0.105 & 0.023 & 0.037 \\
FEV ${ }_{1}$ & 0.006 & -0.243 & -0.058 \\
PEF & -0.137 & -0.190 & 0.077 \\
MIP & -0.197 & -0.142 & -0.045 \\
MEP & -0.175 & 0.298 & -0.072 \\
\hline
\end{tabular}

GMFCS, Gross Motor Function Classification System; FVC, forced vital capacity; $\mathrm{FEV}_{1}$, forced expiratory volume in 1 sec; PEF, peak expiratory flow; MIP, maximal inspiratory pressure; MEP, maximal expiratory pressure.

Results of correlation analysis between the dimensions of diaphragm movement, and respiratory functions and pressures in accordance with the GMFCS levels of the participants are given in the Table 3. There was no significant correlation between the dimensions of diaphragm movement, and respiratory functions and pressures in all of the three groups in accordance with the GMFCS levels of the participants $(P<0.05)$.

\section{DISCUSSION}

Motor function disorders of children with cerebral palsy are important factors that interfere with the development and restoration 
of motor functions as well as further aggravating their participation in social activities since they induce paralysis of respiration muscles, abnormally distorted chest, limitations in physical activities and delay in the development of cardiorespiratory system (Buchanan, 2013). According to the recent research, since the participants with the ambulation capability to perform intense activities diversely can maintain breathing related to physiological functions (Maltais et al., 2005; Slaman et al., 2013), it is asserted that ambulation capability is very important in maintaining and developing respiratory functions. In the results of this study, all of the respiratory functions (FVC, $\mathrm{FEV}_{1}$, and PEF) and respiratory pressures (MIP and MEP) of children with cerebral palsy were found to be significantly higher in GMFCS levels I and II groups in comparison to those of GMFCS level III group. Majority of the children with cerebral palsy in the GMFCS levels I and II groups are able to perform independent ambulation as well as participate in social activities either without any limitation or with some limitations. Since the increase in the motor functions for physical activities enables relatively high efficiency of physiological capacity, it is possible to improve the breathing capabilities (Fowler et al., 2007). However, children with cerebral palsy in the GMFCS level III group who can move about only when they use manual or motorized wheelchair, or hand-operated walking assistance devices such as walker not only lack in cardiorespiratory functions due to limited movement and low level of physical activities but also has relatively high oxygen demand due to low level of physical exercises. Accordingly, such children display insufficient respiratory functions and pressures.

Research by Kwon and Lee (2014), similar to this study, reported that children with cerebral palsy in GMFCS level III group had significantly low respiratory functions and pressures in comparison to those of the children with cerebral palsy in GMFCS levels I and II groups. However, although the preceding research reported that children with cerebral palsy in GMFCS levels I and II groups did not display significant differences in the respiratory functions and pressures due to similar capabilities for physical activities, this study found significant differences in the respiratory functions and pressures between these two groups. Several previous researches reported that respiratory functions and muscle strengths of children with neurological disorder are closely related to extent of daily life activities performed and functional motor abilities (Bosnak-Guclu et al., 2012; Wang et al., 2012). In my opinion, such differences when compared with the findings of the preceding researches is deemed to be the results of the existence of detailed differences when comparison is made from the perspectives of en- vironmental factors, use of auxiliary equipment and participation in social activities, although the levels of the physical activities of the children with cerebral palsy are similar between the two groups. That is, majority of the children in GMFCS level I group are capable of walking under most environments, can walk up and down stairs without having to hold onto the railing and participated in sports activities, although not in complete manner. On the other hand, children in GMFCS level II group can participate in sports activities including ambulation only if they are equipped with auxiliary equipment in accordance with the environment and personal situations.

Since diaphragm, the main muscle involved in breathing, is in charge of approximately $70 \%$ of inspiration at the time of physiologically stable breathing if it is normal (Onders et al., 2014), functional evaluation of diaphragm is clinically very important since it is a composite muscle in the thoracic abdominal area in relation to respiratory function (Anraku and Shargall, 2009). In particular, since children with cerebral palsy breathe when moving by pulling the head and chin back, raising the rib cage upward asymmetrically and while having the mouth opened, it is difficult to structurally and functionally develop the lung including diaphragm through deep breathing of air into the lung. As the results of this study, there were significant differences in the dimensions of diaphragm movement at the time of both spontaneous breathing and deep breathing between children with cerebral palsy in GMFCS levels I and III, and between GMFCS levels II and III. This is because the functional movements and physical functions of children with cerebral palsy in GMFCS levels I and II groups are relatively inadequate in comparison to the children with cerebral palsy in GMFCS level III group, who are capable of conducting independent ambulation and participation in social activities. That is, this difference is due to reduction in the movement of diaphragm when breathing due to limitation in flexible extension and rotation since children with cerebral palsy displays stiffer rib cage and increased immobility of vertebrate with lower level of physical activities. Furthermore, children with cerebral palsy displays the tendency of insufficient breathing with the xiphoid process portion of the central area of the rib cage becoming strongly sunken rather than moving the rib cage by expanding it in each of the front to back, right and left, and up and down directions at the time of inspiration. This is because the diaphragm, anatomically, is attached to the central tendon by being originated from the xiphoid process, ribs numbers $7-12$ and lumbar vertebrates L1-3. That is, since it is more difficult to move the stiff rib cage and vertebrates to inhale when the level of physical activity is lower, 
there is a tendency of excessively pulling the most flexible xiphoid process section among the various origins of the diaphragm rather than having the diaphragm lowered by being contracted, thereby resulting in the characteristic of sinking of the rib cage. It is deemed that there is no difference in the dimensions of diaphragm movements between children with cerebral palsy in GMFCS II and III groups.

In correlation analysis in accordance with the GMFCS levels of children with cerebral palsy, there was no significant correlation between dimensions of diaphragm movement, and respiratory functions and pressures at the time of spontaneous breathing and deep breathing for all the groups of GMFCS levels I-III. Following childbirth, normal children do not breathe only with the movement of diaphragm without the assistance of other muscles, and thoracic abdominal breathing can be performed only when the muscles of the neck and trunk, and posture control is well developed during the time of being able to roll segmentally and sit on his/her own. This is because child can only perform thoracic abdominal breathing as adults do when the respiratory tract is broadened with lowering of the shoulder and rib cage through the development of muscles in neck and upper arm, and when controlling of head and trunk, particularly the muscles developed through rib cage mobility participate in breathing. That is, in the case of normal children, although diaphragm is the main muscle involved in breathing, abdominal muscles such as intercostal muscles, rectus abdominis, internal and external oblique abdominal muscle, and transverse abdominal muscle are well developed and participate in breathing simultaneously to share roles at the time of inspiration and expiration with diaphragm. This results in overall enhancement of breathing capabilities. However, the participants of this study who are children with cerebral palsy with GMFCS levels of I-III tend to lack in their segmental rotation or dissociated movement of the trunk because they are too spastic to perform completed thoracic abdominal breathing like adults, although they can perform major movement motor functions such as rolling and sitting independently. That is, because children with cerebral palsy displays rising of shoulder and rib cage, stiffness of rib cage and lack of sufficient mobility of vertebrates, they display the symptom of diaphragm strongly pulling the xiphoid process section rather than the muscles of neck and truck participating in breathing. Therefore, this is determined to be the reason for absence of correlation between the increase in the dimensions of diaphragm movement, and respiratory functions and pressures.

This study has several limitations. A limitation of this study was that only a small classification of outcomes that focused on spastic type depending on the form of predominant abnormal movement was measured. Another limitation of this study is that only 5-13 years children classified as GMFCS I-III spastic diplegia, were included in this study and so the results cannot be generalized to other GMFCs groups. This trial was also limited by a relatively small sample size. Further study is needed to identify the correlation between diaphragm movement, and respiratory functions and pressures in accordance in children with cerebral palsy classified as various predominant abnormal movement.

As the results of having conducted this study on children with cerebral palsy, there was no significant correlation between the dimensions of diaphragm movement, and respiratory functions and pressures, although there were significant differences in dimensions of diaphragm movement, and respiratory functions and pressures of between children with cerebral palsy in GMFCS levels I-III. That is, it is not possible to determine the overall breathing capabilities such as respiratory functions and pressures only with the dimensions of diaphragm movement of children with cerebral palsy, and to specifically present the extent of dysfunctions in breathing capabilities. Therefore, it is deemed that although measurement of the dimensions of diaphragm movement of children with cerebral palsy by using diagnostic ultrasonic M-mode imaging device can be considered as auxiliary tool in predicting the breathing capabilities, it cannot be used as independent measurement equipment.

\section{CONFLICT OF INTEREST}

No potential conflict of interest relevant to this article was reported.

\section{REFERENCES}

Anraku M, Shargall Y. Surgical conditions of the diaphragm: anatomy and physiology. Thorac Surg Clin 2009;19:419-429, v.

Ayoub J, Cohendy R, Dauzat M, Targhetta R, De la Coussaye JE, Bourgeois JM, Ramonatxo M, Prefaut C, Pourcelot L. Non-invasive quantification of diaphragm kinetics using m-mode sonography. Can J Anaesth 1997; 44:739-744.

Bax M, Goldstein M, Rosenbaum P, Leviton A, Paneth N, Dan B, Jacobsson B, Damiano D; Executive Committee for the Definition of Cerebral Palsy. Proposed definition and classification of cerebral palsy, April 2005. Dev Med Child Neurol 2005;47:571-576.

Bosnak-Guclu M, Gunduz AG, Nazliel B, Irkec C. Comparison of functional exercise capacity, pulmonary function and respiratory muscle 
strength in patients with multiple sclerosis with different disability levels and healthy controls. J Rehabil Med 2012;44:80-86.

Buchanan GF. Timing, sleep, and respiration in health and disease. Prog Mol Biol Transl Sci 2013;119:191-219.

de Almeida IC, Clementino AC, Rocha EH, Brandão DC, Dornelas de Andrade A. Effects of hemiplegy on pulmonary function and diaphragmatic dome displacement. Respir Physiol Neurobiol 2011;178: 196-201.

de Leeuw M, Williams JM, Freedom RM, Williams WG, Shemie SD, McCrindle BW. Impact of diaphragmatic paralysis after cardiothoracic surgery in children. J Thorac Cardiovasc Surg 1999;118:510-517.

Engel-Yeger B, Jarus T, Anaby D, Law M. Differences in patterns of participation between youths with cerebral palsy and typically developing peers. Am J Occup Ther 2009;63:96-104.

Epelman M, Navarro OM, Daneman A, Miller SF. M-mode sonography of diaphragmatic motion: description of technique and experience in 278 pediatric patients. Pediatr Radiol 2005;35:661-667.

Ersöz M, Selçuk B, Gündüz R, Kurtaran A, Akyüz M. Decreased chest mobility in children with spastic cerebral palsy. Turk J Pediatr 2006; 48:344-350.

Fitzgerald DA, Follett J, Van Asperen PP. Assessing and managing lung disease and sleep disordered breathing in children with cerebral palsy. Paediatr Respir Rev 2009;10:18-24.

Fowler EG, Kolobe TH, Damiano DL, Thorpe DE, Morgan DW, Brunstrom JE, Coster WJ, Henderson RC, Pitetti KH, Rimmer JH, Rose J, Stevenson RD; Section on Pediatrics Research Summit Participants; Section on Pediatrics Research Committee Task Force. Promotion of physical fitness and prevention of secondary conditions for children with cerebral palsy: section on pediatrics research summit proceedings. Phys Ther 2007;87:1495-1510.

Knox V, Evans AL. Evaluation of the functional effects of a course of Bobath therapy in children with cerebral palsy: a preliminary study. Dev Med Child Neurol 2002;44:447-460.

Kwon YH, Lee HY. Differences of respiratory function according to level of the gross motor function classification system in children with cerebral palsy. J Phys Ther Sci 2014;26:389-391.

Maltais DB, Pierrynowski MR, Galea VA, Bar-Or O. Physical activity level is associated with the $\mathrm{O}_{2}$ cost of walking in cerebral palsy. Med Sci Sports Exerc 2005;37:347-353.

Mead J, Sly P, Le Souef P, Hibbert M, Phelan P. Rib cage mobility in pectus excavatum. Am Rev Respir Dis 1985;132:1223-1228.

Mok Q, Ross-Russell R, Mulvey D, Green M, Shinebourne EA. Phrenic nerve injury in infants and children undergoing cardiac surgery. $\mathrm{Br}$ Heart J 1991;65:287-292.

Onders RP, Elmo M, Kaplan C, Katirji B, Schilz R. Final analysis of the pilot trial of diaphragm pacing in amyotrophic lateral sclerosis with long-term follow-up: diaphragm pacing positively affects diaphragm respiration. Am J Surg 2014;207:393-397.

Riccabona M, Sorantin E, Ring E. Application of M-mode sonography to functional evaluation in pediatric patients. Eur Radiol 1998;8:1457-1461.

Rosenbaum P, Paneth N, Leviton A, Goldstein M, Bax M, Damiano D, Dan B, Jacobsson B. A report: the definition and classification of cerebral palsy April 2006. Dev Med Child Neurol Suppl 2007;109:8-14.

Seddon PC, Khan Y. Respiratory problems in children with neurological impairment. Arch Dis Child 2003;88:75-78.

Slaman J, Bussmann J, van der Slot WM, Stam HJ, Roebroeck ME, van den Berg-Emons RJ; Transition and Lifespan Research Group South West Netherlands. Physical strain of walking relates to activity level in adults with cerebral palsy. Arch Phys Med Rehabil 2013;94:896-901.

Urvoas E, Pariente D, Fausser C, Lipsich J, Taleb R, Devictor D. Diaphragmatic paralysis in children: diagnosis by TM-mode ultrasound. Pediatr Radiol 1994;24:564-568.

Voyvoda N, Yücel C, Karatas G, Oguzülgen I, Oktar S. An evaluation of diaphragmatic movements in hemiplegic patients. Br J Radiol 2012;85: 411-414

Wang HY, Chen CC, Hsiao SF. Relationships between respiratory muscle strength and daily living function in children with cerebral palsy. Res Dev Disabil 2012;33:1176-1182. 